\title{
Effect of Tool-Path on Morphology and Mechanical Properties of Ti-6Al-4V Fabricated by Wire and Arc Additive Manufacturing
}

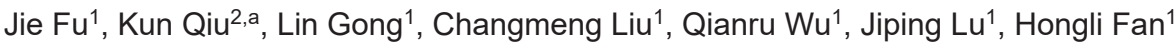 \\ ${ }^{1}$ School of Mechanical Engineering, Beijing Institute of Technology, Beijing, Zhongguancun south Street, 100081, China \\ ${ }^{2}$ School of Mechanical Engineering, Beijing Polytechnic, Beijing, 100176, China
}

\begin{abstract}
Ti-6Al-4V components are widely used in aerospace industry. However, it's not economic to manufacture them in traditional subtractive methods. Wire and arc additive manufacturing (WAAM) is a promising alternative technology for fabricating it efficiently and economically. Tool-path planning strategy is a very important step in WAAM process. This paper investigated the influence of the lap way between layers and layers in tool-path on the Ti-6Al-4V samples fabricated by WAAM. It has been found that the lap way between layers and layers in tool-path do influence the forming quality and especially mechanical properties of the fabricated samples. Samples have different surface quality (smooth or undulating) and defects inside or on the surface of the components. The highest and smallest ultra tensile strength of the fabricated samples are respectively $907.86 \mathrm{MPa}, 684.82 \mathrm{MPa}$. But it has few effect on the grains of the fabricated samples, and they all have cross-sectional columnar grains.
\end{abstract}

\section{Introduction}

Wire and arc additive manufacturing (WAAM) is a promising technology in the aerospace industry manufacturing titanium alloy parts. As a method of additive manufacturing, it can fabricate any complex component with near net shape and without any mold, while saving materials, reducing manufacturing costs and shortening the production cycle. Compared with other additive manufacturing methods, such as Selective Laser Melting (SLM), Electron Beam Direct Manufacturing (EBDM), it fabricates the component with higher forming efficiency and lower costs. So it has grained more and more attention in the last decades [1-4].

Gas Tungsten Arc Welding (GTAW) [5] and Plasma Arc Welding (PAW) [6] are the two main methods of WAAM. Compared with PAW, GTAW is simple to control, has less process parameters, and the arc in the deposition process is relatively stable, make it easy to improve and research.

In the deposition process, many factors have an impact on the forming quality. Jun Xiong et al. [7] used a parabolic model, a cosine model, and a circular model to simulate the cross section profile of the welding in the WAAM, and select the deposit spacing as two thirds of the welding width. His experiments found that the ratio of wire feed rate to welding speed greatly influence the shape of the welding profile. Donghong Ding et al. [8] proposed a new multi-bead overlapping model for WAAM which set the deposit spacing to 0.738 times welding width and the fabricated components have a smoother surface. In addition to the deposit spacing, tool- path planning is also an important part of the impact of forming surface quality. There are now five main toolpath used in the WAAM process: raster, zigzag, contours, and continuous[9]. The zigzag tool-path is the most popular method used in WAAM process, and many papers have already researched it $[10,11]$. But for the lap way between layers and layers, there are few researches.

Thus, the aim of this paper is to investigate the effect of the lap way between layers and layers on the morphology and mechanical properties of the Ti-6Al-4V samples fabricated by GTAW.

\section{Experiment}

The additive manufacturing equipment used in this study was assembled by Beijing Institute of Technology as shown in Figure 1. It can be divided into four parts: control system, wire feeding system, argon protection system and welding machine as shown in .Control system controls welding machine arc switch, wire feeder switch and machine movement. The wire feeding system controls the wire feeding speed. Argon protection system to transport argon, protect the workpiece, to avoid oxidation of titanium alloy at high temperatures. Welding machine is responsible for providing arc and controls peak current, pulse frequency, peak time ratio, base-topeak current ratio and other parameters.

The components will be fabricated on the Ti-6Al-4V titanium alloy substrates with the size of $150 \mathrm{~mm} \times 50 \mathrm{~mm}$ $\times 5 \mathrm{~mm}$. The process parameters used in the deposition process is shown in Table 1.

\footnotetext{
${ }^{\mathrm{a}}$ Corresponding author: gonglin@bit.edu.cn
} 
Four kinds of tool-path were used in this experiment as shown in Figure 2 and the direction was also marked on it. They are all made up of zigzag paths. Their difference lies in the lap way between layers and layers. The first and third tool-path schemes are the same for repeated scaninng, the difference is that one is mainly for the side wire feeding, one for the front and back feeding to testing the influence of the wire-feeding directions as shown in Figure 2a\&c [12]. The layer is interlaced with the previous layer in the second tool-path scheme as show in Figure 2b. Each layer is moved $3 \mathrm{~mm}$ outward in the horizontal direction. The tool-path between the layers are symmetrical in the fourth tool-path scheme as shown in Figure 2d. The first three scheme do not require arc failure in the scanning process, and the fourth scheme requires arcing and arc failure at each layer. Each scheme has ten layers.

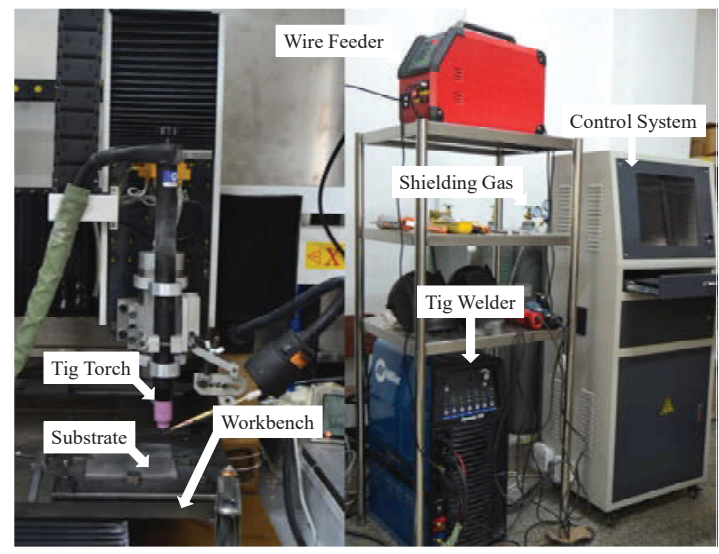

Figure 1 Experimental Equipment

Table 1 Deposition parameters used in this study

\begin{tabular}{|c|c|c|}
\hline Parameter name & Unit & Values \\
\hline Wire feed speed & $\mathrm{mm} / \mathrm{min}$ & 1000 \\
\hline Peak current & $\mathrm{A}$ & 260 \\
\hline Pulse frequency & $\mathrm{Hz}$ & 1.8 \\
\hline Peak time ratio & $\%$ & 40 \\
\hline $\begin{array}{c}\text { Base-to-peak } \\
\text { current ratio }\end{array}$ & $\%$ & 5 \\
\hline Scanning speed & $\mathrm{mm} / \mathrm{min}$ & 360 \\
\hline Layer thickness & $\mathrm{mm}$ & 1.1 \\
\hline Deposit spacing & $\mathrm{mm}$ & 5.5 \\
\hline Wire feed angle & ${ }^{\circ}$ & 45 \\
\hline $\begin{array}{c}\text { Electrode to } \\
\text { workpiece distance }\end{array}$ & $\mathrm{mm}$ & 8 \\
\hline
\end{tabular}

After forming process, three tensile specimens perpendicular to the weldings were obtained in the horizontal plane of each sample by wire-cutting techniques. Static tensile tests at room temperature were carried out on an INSTRON 5966 material testing machine. The max load capacity of it is $10 \mathrm{kN}$ and the drive type is powerful motors. The strain is acquired by video-extensometer. The cross-head displacement speed was $0.01 \mathrm{~mm} / \mathrm{s}$.

The samples for microstructural characterization were be obtained from XZ plane by wire-cutting techniques. The samples were firstly polished with $\mathrm{SiC}$ paper (180, $360,600,1000,2000)$, then etching for $20 \mathrm{~s}$ using a solution consisting of 2\% HF (hydrofluoric acid) and 6\% HNO3 (nitric acid). All the grains size were determined by ImageJ software.
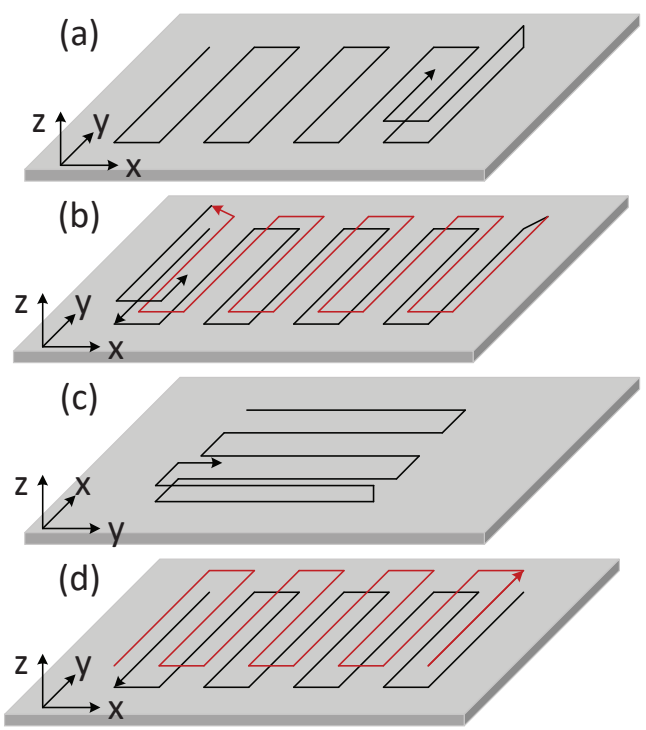

Figure 2 The four tool-path used in the experiment

\section{Results}

\subsection{Macrostructure}

The four fabricated samples are shown in Figure 3. In general, four samples were successfully formed. The molten pool was arranged in an orderly manner like fish scales. There is also a phenomenon that can not be ignored, from one side of the welding to the other side, the molten pool size gradually becomes larger or smaller especially in Figure 3c. Samples A, D are free of defects and their surface are flat. Samples B, C have a defect on the surface. Samples B, D appear splashing.

The contours of the upper and lower sides of the four samples are shown in Figure 4. It can be seen from the figure: the sample A, C contour fluctuation degree of the largest, the sample D is the most smooth. It shows that the lap way between layers and layers do influence the forming quality.

As the tool-path is zigzag, during the scanning process, when the torch gun scan to the turning point, the heat accumulation, the temperature rise, resulting in increased molten pool size. when scanning long welding, the temperature gradually decreased, the molten pool size changes small, therefore from one side of the welding to the other side, the molten pool size gradually becomes larger or smaller, resulting in lateral contours fluctuate up and down, as shown in Figure 5. So the lateral contours of sample $A \& C$ fluctuate up and down, followed by the sample B, and sample D is the most smooth. Because the tool-path between the layers are symmetrical in the fourth scheme, the tool-path between layers and layers form a complementary, eliminating fluctuations in the lateral profile, forming a smooth side profile. 

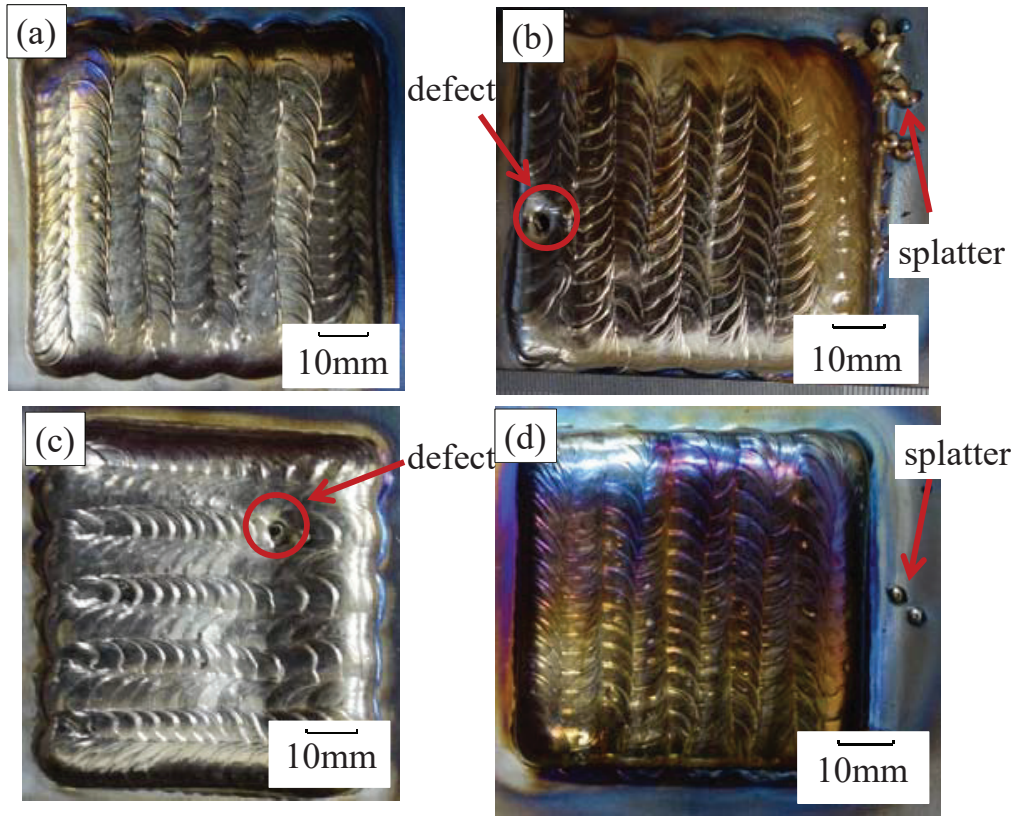

Figure 3 The fabricated samples, correspond to the tool-path shown in Figure 2. (a) sample A, (b) sample B, (c) sample C, sample D.

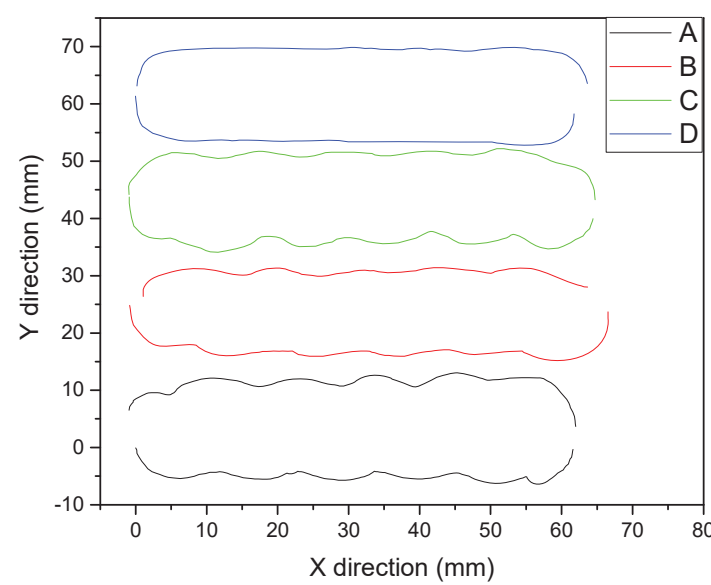

Figure 4 The contours of the upper and lower sides of the four samples

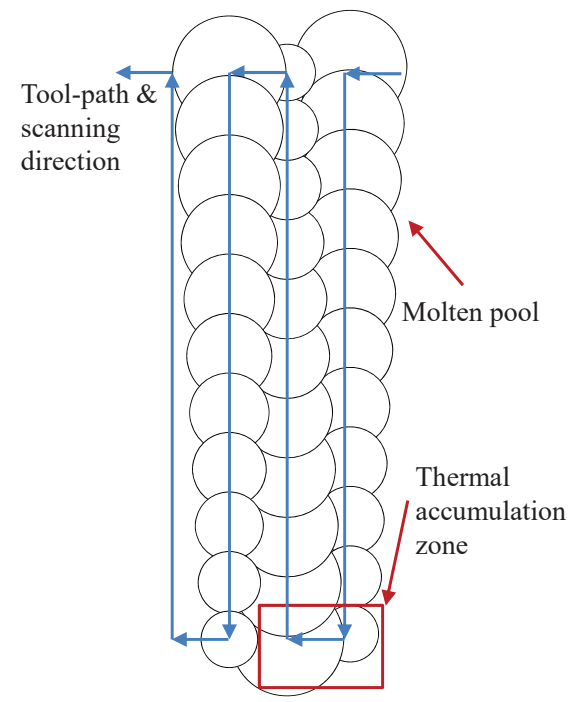

Figure 5 The schematic of the formation of molten pool size

\subsection{Grains and Morphology}

The macrostructure of the fabricated samples is shown in Figure 6. It's obvious that the bottom part (substrate) of the four samples are equiaxed grains, and the forming parts are formed into columnar grains throughout the samples. The average width of the columnar grains from each sample is $0.664 \mathrm{~mm}, 0.946 \mathrm{~mm}$, $0.899 \mathrm{~mm}, 1.371 \mathrm{~mm}$. The columnar grains of each sample are not significantly different in shape and size. It indicates that the tool-path has few effect on the macrostructure of the fabricated samples.

Sample A, C, D appeared not obvious defects, sample $B$ appeared lots of defects and holes. The differences of the $\mathrm{z}$ coordinate between the highest point and the lowest point of the cross section profile of each sample stabilized part are $3.371 \mathrm{~mm}, 0.943 \mathrm{~mm}, 1.267 \mathrm{~mm}$, $1.962 \mathrm{~mm}$.
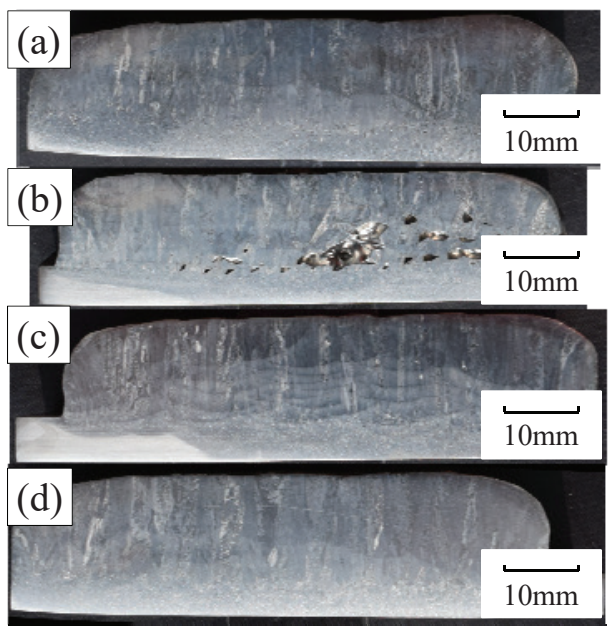

Figure 6 Macrostructure of the fabricated samples: all columnar grains throughout the samples 


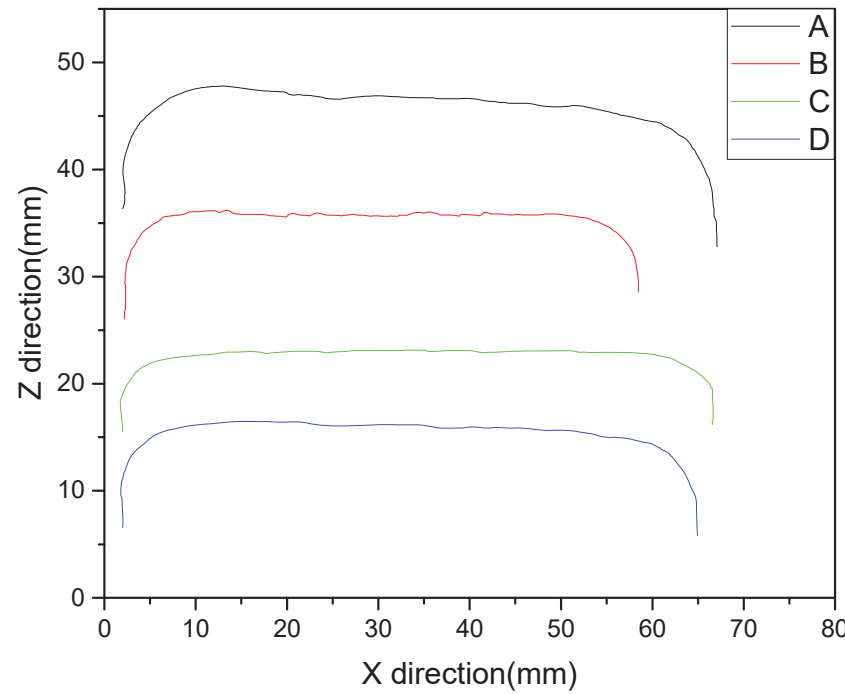

Figure 7 The contours of the cross section of the fabricated samples.

\section{Mechanical properties}

The results of the static tensile tests at room temperature are shown in Figure 9. From sample A to D, the average ultra tensile strength (UTS) of each sample is: 907.86 $\mathrm{MPa}, 876.82 \mathrm{MPa}, 791.75 \mathrm{MPa}, 684.82 \mathrm{MPa}$. the average strain of each sample is $5.93 \%, 11.74 \%, 10.91 \%$, $8.37 \%$. Sample A has the highest ultra tensile strength, while sample B has the highest strain, and the strength and strain of sample D are the worst.

The tensile results of the sample A\&C shows that the wire-feeding direction influence the mechanical properties of the fabricated samples. The tensile results of the samples indicate that tool-path influence the UTS and strain of the fabricated samples in WAAM process.

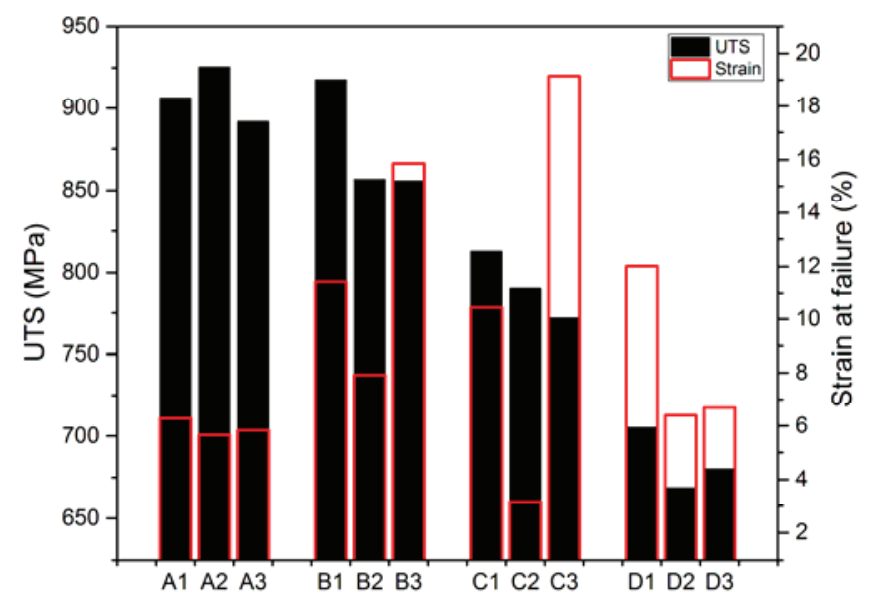

Figure 8 Ultimate tensile strength and strain of the sample fabricated by WAAM.

\section{Conclusion}

In this paper, the influences of tool-path on the fabricated samples in WAAM process was investigated. Sample B shows splatter outside and defects, holes inside. Sample C shows defect outside and has fluctuating sides.
Although sample D has a very smooth surface, it has splatter outside and has the worst mechanical properties. Sample A performed well in all respects except in side profile, but this is not a disadvantage, it meets the requirements of forming quality.

The results of this paper shows that the lap way between layers and layers do influence the morphology and mechanical properties of the Ti-6Al-4V samples fabricated by GTAW. The simpler the lap way, the better performance of the fabricated samples.

\section{References}

1. Williams SW, Martina F, Addison AC, Ding J, Pardal G, Colegrove P. Mater Sci Technol, 641-7, 32 (2016).

2. Ding D, Pan Z, Cuiuri D, Li H. Int J Adv Manuf Technol. 465-81, 81 (2015).

3. Baufeld B, Biest O V D, Dillien S. Metallurgical \& Materials Transactions A. 1917-1927, 8 (2010).

4. $\mathrm{Wu} \mathrm{Q}, \mathrm{Ma} \mathrm{Z}$, Chen $\mathrm{G}$, et al. Journal of Manufacturing Processes, 198-206, 27 (2017).

5. Wang, F., Williams, S., Colegrove, P., \& Antonysamy, A. A. Metallurgical \& Materials Transactions A. 968-977, 2 (2013),

6. Martina F, Mehnen J, Williams S W, et al. Journal of Materials Processing Technology. 1377-86, 6 (2012).

7. Xiong J, Zhang G, Gao H, et al. Robotics and Computer Integrated Manufacturing. 417-423, 2 (2013).

8. Ding D, Pan Z, Cuiuri D, et al. Robotics \& Computer Integrated Manufacturing, 101-110, C (2015).

9. Ding D H, Pan Z X, Dominic C, et al. Springer International Publishing, 437-450, (2015).

10. Park S C, Choi B K. K.: Computer-Aided Design, 17-25, 1 (2000).

11. Tarabanis K A, Rajan V T, Srinivasan V. Rapid Prototyping Journal, 231-241,5 (2001).

12. Fu J, Gong L, Zhang Y, et al. Applied Sciences, 227, 3 (2017). 